\title{
Memórias, em perspectivas
}

\author{
Emilia Pietrafesa de Godol, Unicamp, e \\ Cintya Maria Costa Rodrigues, UFG
}

$\mathrm{R}$ EUNIMOS NESTE DOSSIÊ artigos que contribuem para a reflexão sobre memória social e os temas que lhe são correlatos como história oral, oralidade, trajetórias e narrativas. Todos eles refletem sobre estas temáticas de uma maneira inovadora, rompendo concepções já cristalizadas nas ciências humanas que nos remetem à equação memória: lugar: cultura. Além disso, os artigos apresentam-nos diferentes contextos em várias escalas - local regional, nacional e internacional; cruzam diversos olhares, reconstituindo o ínfimo cotidiano e encontrando o detalhe pertinente; seguindo trajetórias de pessoas no espaço e até no ciberespaço; tomando como agentes sociais grupos etários pouco considerados no tratamento destes temas; trazendo as dimensões de gênero e etnicidade na construção de memórias e refletindo sobre o lugar do oral e do escrito nas narrativas antropológicas. A memória tratada aqui não está estagnada sobre o peso do passado, nem encarregada de explicá-lo, tampouco de prever o futuro, mas permite criar uma 'duração' própria, na qual pessoas se sentem ligadas por experiências partilhadas.

Quem jamais pensou que se pudesse perscrutar a memória social e a história de famílias inteiras pela comida? Pois é tomando as práticas alimentares como narrativas e assim revelando a sua dimensão comunicativa, que Renata Menasche e Denise Amon vão nos revelar experiências de uma família judia sefardi radicada no Brasil, um artigo saboroso e eloqüente. Esse suporte da memória, as práticas alimentares, não são aquelas rituais como facilmente poder-se-ia imaginar - as associadas a festividades e celebrações -, mas aquelas triviais e cotidianas, muito embora as autoras estejam atentas para o fato de que, sobretudo com as migrações, pode haver deslocamentos de práticas alimentares do cotidiano para o ritual. $\mathrm{O}$ argumento central das autoras é o de que a comida conta histórias. Por meio dela pode ocorrer a afirmação de identidades, pois é expressão de um sentimento de pertença, além de ser ela mesma parte de um 'sistema de pertinências'. No entanto, a comida não é somente a afirmação 'do mesmo'; expressa também mudanças e negociações de sentidos. Renata Menasche e Denise Amon mostram como a narrativa da comida constrói a comunidade e, nesse caminho, apresentam-nos o movimento transgeracional da construção de um 'paladar coletivo' e os gostos são apurados e transmitidos. O tema da comida entrelaça-se com o assunto da transmissão intergeracional de forma inovadora, destacando-se o sentido da 'receita culinária' como veículo dessa transmissão e lugar de um conteúdo e de um 'modo de fazer' significativo para uma coletividade ${ }^{1}$.

Em outro artigo, a dimensão do gênero está presente na transmissão e transmissibilidade de uma memória por meio de mulheres tendo como suporte as práticas alimentares. Nesse artigo, soma-se a esta dimensão, outras como a da etnicidade e a da condição de jovem e imigrante. É cruzando essas várias dimensões que o artigo de Neusa Maria Mendes de Gusmão vai analisar as narrativas de duas jovens mulheres africanas em Portugal. O olhar e os ouvidos atentos da pesquisadora

1 Uma discussão mais específica sobre o tema da transmissão intergeracional encontra-se em Bertaux , e Thompson ,1993. 
captam para além das trajetórias pessoais dessas duas jovens. Ficamos sabendo que antes de chegarem a Portugal, os imigrantes africanos circulam pelo próprio mundo africano, as redes de parentes nos distintos lugares orientam esses deslocamentos. Mediante a descrição da 'vida vivida' nos bairros periféricos de Lisboa, toma-se conhecimento do avanço e modernização urbana sobre áreas de ocupação da periferia lisboense e das chamadas políticas sociais voltadas para os migrantes extra-comunitários, vistos como problemáticos para os planos da União Européia. Ligando as trajetórias pessoais com a realidade portuguesa, a autora não oblitera na construção que estas jovens fazem de suas histórias de vida a influência de aspectos próprios da experiência prévia em seus países de origem, em particular aquela relativa às práticas e papéis femininos.

Quando se fala em história oral e memória logo se pensa em quem as produz/transmite e em que circunstâncias. Logo se pensa em velhos e em experiências que legitimam uma memória. O dossiê traz um artigo sobre jovens mulheres como agentes sociais do 'trabalho com e da memória'. Entretanto, raros são os trabalhos que tomam meninos e meninas como agentes sociais, dando atenção às particularidades de seus olhares e narrativas. No artigo de Diana Milsten está, pois, em discussão o estatuto das falas de meninos e meninas na narrativa antropológica. Tendo iniciado a pesquisa preocupada em observar as práticas escolares em sua dimensão política, em uma escola primária estatal argentina (Villa La Florida, Partido de Quilmes) partindo do que faziam e diziam os adultos, começa a perceber que meninos e meninas narravam situações e mostravam conhecimentos pertinentes à pesquisa. $\mathrm{O}$ olhar etnográfico da autora volta-se, então, para as suas narrativas, para as versões que construíam sobre a vida do bairro e da escola, integrando um grupo de alunos/as como seus colaboradores, conferindo-lhes estatuto de interlocutores, entrevistadores e observadores. $\mathrm{O}$ artigo de Diana Milsten é, pois, um convite para 'levar a sério' a(s) perspectiva(s) das crianças.

Se no artigo precedente a autora nos leva a pensar no estatuto que diferentes grupos etários recebem no tratamento de histórias locais e de memórias na construção das narrativas antropológicas, o artigo de Marcelo Moura Mello traz uma instigante reflexão sobre o tratamento teórico e metodológico que tem sido dado à oralidade na sua relação com o escrito. As 'mutações do olhar' referem-se às modificações da percepção e tratamento dispensados pelo próprio autor ao dito e ao escrito, ao estatuto que essas formas foram adquirindo no decorrer de sua pesquisa na Comunidade Negra Rural de Cambará (RS). Nesse artigo, o autor toma a oralidade 'nos seus próprios termos', descrevendo os contextos e as formas de lembrar, superando a perspectiva que toma os relatos orais como formas imprecisas e vagas de registro do passado por oposição à veracidade histórica do documento escrito. Reflete, pois, sobre o lugar do oral e do escrito na construção das narrativas antropológicas e, em diálogo com diversos autores, abre novas possibilidades. A utilização de arquivos como fonte de conhecimento antropológico é cada vez mais assumida e valorizada pelos pesquisadores contemporâneos ao se depararem com certos contextos etnográficos. O artigo de Marcelo Melo mostra que associar o uso das fontes arquivísticas com a produção etnográfica é admitir um diálogo inescapável entre oralidade e escrita, entre 'memórias' localizadas em dimensões que se relacionam ${ }^{2}$.

2 Em 2005 a revista Estudos Históricos publicou um dossiê tratando das relações entre o campo e o arquivo. Estudos Histórico - Antropologia e Arquivos, 2005, e também Cunha ,(19..). 
O autor toca no que se pode nomear de "memórias traumáticas" (Gagnebin, 2004, p.85-94) difíceis e necessárias, e que estão presentes também em uma "literatura de testemunho", mas não somente, como nos mostra o artigo de Maria Luiza R. Souza, tomando "filmes-testemunhos”. Adotando uma narrativa etnográfica da narrativa fílmica, Maria Luiza R. Souza toma para análise dois filmes, cujas narrativas tratam de histórias sobre militantes da luta contra a ditadura no período compreendido entre 1964 e 1985. Antes, porém, faz uma leitura deste período, propondo que houve 'formação de uma cultura do terror que passou a cobrir a vida social', numa clara inspiração na leitura de Taussig sobre o mundo colonial, mas também sobre outras situações onde o controle de 'populações, classes sociais e nações' se colocam. Os filmes analisados são vistos como 'formas de acesso às memórias do período ditatorial e às formas como se conta o passado' e passam eles próprios a se constituir como um suporte de memória.

Os artigos precedentes refletiram, entre vários aspectos, sobre o lugar do oral e do escrito nas narrativas antropológicas e sobre distintos suportes da memória, como arquivos e filmes, enquanto o artigo de Luciana Hartmann vai tomar a oralidade como objeto de reflexão. A autora argumenta que a relação que os habitantes da região de fronteira entre Argentina, Brasil e Uruguai têm desenvolvido tradicionalmente com a oralidade constitui um dos principais aspectos que compõem a cultura da fronteira. Demonstra a existência de uma rede de contadores e ouvintes nas fronteiras entre esses três países, que compartilham um conhecimento e usos de 'códigos de linguagem verbal e corporal, apropriados'. Por isso fala em 'comunidade narrativa' propondo que esta deve ser pensada como um 'dispositivo analítico' que permite dar conta do emprego de diferentes idiomas no contexto da 'cultura da fronteira', sobretudo no momento da narração de histórias: em uma mesma narrativa têm-se expressões em espanhol e em português a depender da audiência.

O artigo de Luciana Hartmann nos leva a pensar em uma memória que não só atravessa fronteiras, mas se constitui mesmo nesse deslocamento. Como pensar a memória que não esteja ancorada em um espaço bem definido, ou melhor, como pensá-la com o espaço virtual, do ciberespaço? Mostrando a constituição de uma comunidade on-line, o artigo de Jean Segata vai trabalhar a construção coletiva de memória(s) de um tempo vivido por pessoas que nas suas trajetórias de vida se deslocaram espacialmente, mas baseadas na pequena cidade do interior de Santa Catarina. Assim, com a contribuição das várias pessoas que se encontraram no espaço virtual, aos poucos foi se fazendo com que os membros daquela comunidade, nas palavras de um participante: 'se sentissem em casa de novo', em uma palavra 'localizada'. Este artigo põe, pois, em discussão a relação entre globalidade e localidade e, mais do que isso, nos remete a algo que em termos do pensamento de Walter Benjamin é pensado como o "fim da narração e da narrativa tradicional", resultante, entre outros fatores, da transformação da sociabilidade nas sociedades modernas, marcada pela impessoalidade e individualização.

Esta última observação nos faz lembrar, como já advertiu. Gagnebin (2004, p.85), que o pensamento de W. Benjamin sobre a memória nos legou questões não resolvidas 'e que ainda são nossas'. Os artigos deste dossiê se defrontam e lidam com algumas delas, como as dificuldades decorrentes de experiências de sofrimento e dor que pesam sobre a possibilidade da narração; ainda, a possibilidade, entre tantos deslocamentos, da experiência compartilhada, retomada e transformada a cada geração; e mais, a "possibilidade da transmissão e do lembrar" (Gagnebin, 2004, p.91). 
Ao organizar esse dossiê diante dos artigos que o compõe, refletimos sobre as amplas possibilidades oferecidas pelos estudos de memória, sobre o que ainda temos para aprender e aguardar desse assunto. As potencialidades são inesgotáveis e o que os artigos mostram é que há uma abertura para a entrada em cena de novos atores, pouco considerados, como as crianças; para a utilização de combinações interdisciplinares de metodologias - a história oral, os arquivos e a etnografia; para outras incursões em temas conhecidos - a transmissão intergeracional e a produção da oralidade; para os diferentes contextos e espaços de atuação da memória - o ciberespaço, a fronteira; para os suportes inusitados da memória - a receita culinária, as imagens; e, finalmente, para aqueles 'componentes da memória' que fornecem significados para os demais os sentimentos, as emoções: Como refletir sobre os traumas e os dramas pessoais e coletivos? Observem, finalmente, a forma sistêmica com que muitos dos aspectos tratados nos artigos - as imagens, as relações, as pessoas, as histórias, os espaços e os escritos - informaram as memórias em movimento, presentificadas em situações contemporâneas e cotidianas, inseridas em processos de construção de identidades.

Esta apresentação constitui-se, assim, em um convite ao leitor para acompanhar como os autores que participam deste dossiê lidaram com essas e outras questões postas pelo trabalho com, sobre, pela e da memória.

\section{Referências}

BERTAUX, Daniel; THOMPSON, Paul. Between Generations - family models, myths and memories. New York, USA, Oxford University Press Inc, 1993.

CUNHA, Olivia Maria Gomes da. Tempo imperfeito: uma etnografia no arquivo. Mana - Estudos de Antropologia Social, v. 10, n.2, p. 287-322, 2004.

GAGNEBIN, J. M. Memória. História, testemunho, memória e (re)sentimento: indagações sobre uma questão sensível. Stella Bresciani e Márcia Naxara (Org.). Campinas, Editora da Unicamp, 2004, p. 85-94. 